\title{
Correction to: Atraumatic femoral neck fracture during bisphosphonate treatment: case report and review of the literature
}

\author{
Robert Wilk ${ }^{1}$ (D) Damian Kusz ${ }^{1} \cdot$ Hanna Grygiel $^{2} \cdot$ Magdalena Grosiak $^{2} \cdot$ Jakub Kamiński $^{1} \cdot$ Marcin Kusz $^{2}$
}

Published online: 21 November 2017

(c) The Author(s) 2017. This article is an open access publication

\section{Correction to: Aging Clin Exp Res \\ https://doi.org/10.1007/s40520-017-0846-0}

The article "Atraumatic femoral neck fracture during bisphosphonate treatment: case report and review of the literature", written by Robert Wilk, Damian Kusz, Hanna Grygiel, Magdalena Grosiak, Jakub Kamiński and Marcin Kusz, was originally published electronically on the publisher's internet portal (currently SpringerLink) on October 27, 2017 without open access.

With the author(s)' decision to opt for Open Choice the copyright of the article changed on November 14, 2017 to
(C) The Author(s) [2017] and the article is forthwith distributed under the terms of the Creative Commons Attribution [continuing for CC BY license].

4.0 International License (http://creativecommons.org/ licenses/by/4.0/), which permits use, duplication, adaptation, distribution and reproduction in any medium or format, as long as you give appropriate credit to the original author(s) and the source, provide a link to the Creative Commons license, and indicate if changes were made.

The original article has been corrected.

The online version of the original article can be found under https://doi.org/10.1007/s40520-017-0846-0.

\section{Robert Wilk}

drrobertwilk@gmail.com

1 Department of Orthopaedics and Traumatology, School of Medicine in Katowice, Medical University of Silesia in Katowice, Ziołowa 45/47 Street, 40-635 Katowice, Poland

2 Department of Orthopaedics and Traumatology, Students' Scientific Society, School of Medicine in Katowice, Medical University of Silesia in Katowice, Katowice, Poland 